\title{
Production of Mycophenolic Acid by a Newly Isolated Indigenous Penicillium glabrum
}

\author{
Fatemeh Mahmoudian ${ }^{1} \cdot$ Atefeh sharifirad $^{1,2} \cdot$ Bagher Yakhchali $^{1} \cdot$ Saham Ansari ${ }^{3} \cdot$ Seyed Safa-ali Fatemi ${ }^{1}$ (D)
}

Received: 9 April 2020 / Accepted: 25 April 2021 / Published online: 21 May 2021

(c) The Author(s), under exclusive licence to Springer Science+Business Media, LLC, part of Springer Nature 2021

\begin{abstract}
Soil-occupant fungi produce a variety of mycotoxins as secondary metabolites, one of which is mycophenolic acid (MPA), an antibiotic and immunosuppressive agent. MPA is mainly produced by several species of Penicillium, especially Penicillium brevicompactum. Here, we present the first report of MPA production by a local strain belonging to Penicillium glabrum species. We screened ascomycete cultures isolated from moldy food and fruits, as well as soils, collected from different parts of Iran. MPA production of one hundred and forty Penicillium isolates was analyzed using HPLC. Three MPA producer isolates were identified, among which the most producer was subjected to further characterization, based on morphological and microscopic analysis, as well as molecular approach (ITS, rDNA and beta-tubulin gene sequences). The results revealed that the best MPA producer belongs to P. glabrum IBRC-M 30518, and can produce $1079 \mathrm{mg} / \mathrm{L}$ MPA in Czapek-Dox medium.
\end{abstract}

\section{Introduction}

Mycophenolic acid (MPA) is an antibiotic and immunosuppressant drug which is commercialized as mycophenolate mofetil (MMF) and mycophenolate sodium for the prevention of organ transplant rejection [1,2]. MPA and its derivatives have diverse biological properties and have been extensively studied for their antineoplastic, anti-inflammatory, anti-psoriasis, antifungal and antiviral activities [3, 4]. Recent reports indicate anti-SARS-CoV-2 activity of MPA [5]. It is a selective and non-competitive inhibitor of the enzyme Inosine Monophosphate DeHydrogenases (IMPDH) involving in de novo biosynthesis of guanosine nucleotide, the only supporting pathway of purines synthesis in both B and $\mathrm{T}$ lymphocytes [4]. Inhibition of IMPDH arrests cell

Seyed Safa-ali Fatemi

sfatemi@nigeb.ac.ir

1 Department of Systems Biotechnology, Institute of Industrial and Environmental Biotechnology, National Institute of Genetic Engineering and Biotechnology (NIGEB), Tehran, Iran

2 Present Address: Department of Medical Biotechnology, Pasteur Institute of Iran, Tehran, Iran

3 Department of Parasitology and Mycology, School of Medicine, Shahid Beheshti University of Medical Sciences, Tehran, Iran proliferation as a result of DNA and RNA biosynthesis blocking $[2,6]$.

MPA is a meroterpenoid consisting of a polyketide nucleus connected to farnesyl pyrophosphate; a mevalonate pathway C-15 intermediate [7]. This metabolite is produced by several Penicillium spp, among which $P$. brevicompactum and $P$. stoloniferum indicate a relatively high ability of production. MPA producing strains of this genus are very common in forest soil, greenhouse and farmland all over the world [8]. Furthermore, these species could be found in moldy food, fruit and dairy products [9-12]. Penicillium glabrum is a filamentous fungus, belonging to the section Aspergilloides. It has a worldwide distribution, frequently encountered in the food manufacturing industry. It is one of the main causes of post-harvest fruit and vegetable rots and food contamination [13]. It has been previously isolated from a wide range of food products such as cheese, maize, rice, jam and bottled water [14]. There is no report on MPA production by $P$. glabrum.

The aim of this study was to isolate a Penicillium MPA producer in the hope to be suitable for large scale production of MPA. 


\section{Materials and Methods}

\section{Isolation of Penicillium Species}

Samples were collected mostly from garden, greenhouse and farmland soils of various provinces of Iran, as well as moldy food, fruit and dairy products. Soil samples were taken from $10 \mathrm{~cm}$ depths with a sterile spatula [15]. $5 \mathrm{~g}$ of each sample were mixed with $50 \mathrm{~mL}$ peptone water $(1 \%)$ containing $0.01 \%$ tween 80 [16]. A serial dilutions up to $10^{-5}$ of supernatant of each sample were prepared [15]. Finally, $100 \mu \mathrm{L}$ of each dilution was spread on two potato dextrose agar (PDA) plates containing $30 \mu \mathrm{g} / \mathrm{mL}$ of Chloramphenicol and Kanamycin, to prevent bacterial growth. The plates were incubated in a dark place at $25-28{ }^{\circ} \mathrm{C}$ for 5-7 days [17].

\section{Single Spore Isolation}

Macroscopic observation of cluster structures and broom handles of each Penicillium was performed using a stereomicroscope. Then a suspension of Penicillium spores in sterile distilled water was prepared. The number of conidia in each water droplet was adjusted between one and 10 after spore count with a Neobar slide. A droplet of suspension was spread on PDA plates and incubated at $25-28{ }^{\circ} \mathrm{C}$ for $24 \mathrm{~h}$. Purified colonies were used for further studies [18].

\section{Penicillium Cultivation and Sample Preparation}

MPA production was analyzed in Czapek-Dox $(\mathrm{Cz})$ medium comprised (g/L): Sucrose, $30 ; \mathrm{NaNO}_{3}, 3 ; \mathrm{K}_{2} \mathrm{HPO}_{4} \cdot 3 \mathrm{H}_{2} \mathrm{O}$, $1.3 ; \mathrm{MgSO}_{4} \cdot 7 \mathrm{H}_{2} \mathrm{O}, 0.5 ; \mathrm{KCl}, 0.5 ; \mathrm{FeSO}_{4} .7 \mathrm{H}_{2} \mathrm{O}, 0.01$; $\mathrm{CuSO}_{4} .5 \mathrm{H}_{2} \mathrm{O}, 0.005 ; \mathrm{ZnSO}_{4} \cdot 7 \mathrm{H}_{2} \mathrm{O}, 0.01[19,20]$. A spore suspension from fresh colonies in sterile distilled water containing $2.5 \times 10^{7}$ spores was used for inoculation of $50 \mathrm{~mL} \mathrm{Cz}$ medium which incubated at $25-28{ }^{\circ} \mathrm{C}$ for 12 days at $180 \mathrm{rpm}$. MPA biosynthesis started after approximately $120 \mathrm{~h}$ (5 days) and was reached the maximum concentration at $300 \mathrm{~h}$ (12 days) [4]. $1 \mathrm{~mL}$ of each culture was centrifuged in $5000 \times g$ at $4{ }^{\circ} \mathrm{C}$ for $5 \mathrm{~min}$ and the supernatant was filtered through $0.2 \mu \mathrm{m}$ filter (Millipore, USA). The filtered samples were stored at $-20{ }^{\circ} \mathrm{C}$ for subsequent analysis.

The MPA production was also investigated in $\mathrm{Xu}$ medium consisted of $(\mathrm{g} / \mathrm{L})$ : glucose, 100; glycine, 14; 1-methionine, $0.5 ; \mathrm{KH}_{2} \mathrm{PO}_{4}, 2.0 ; \mathrm{MgSO}_{4} .7 \mathrm{H}_{2} \mathrm{O}, 1.0$; $\mathrm{FeSO}_{4} .7 \mathrm{H}_{2} \mathrm{O}, 2.2 ; \mathrm{CuSO}_{4} .5 \mathrm{H}_{2} \mathrm{O}, 0.3 ; \mathrm{ZnSO}_{4} .7 \mathrm{H}_{2} \mathrm{O}, 2.4$; $\mathrm{MnSO}_{4} .4 \mathrm{H}_{2} \mathrm{O}, 0.16$; and $\mathrm{KMoO}_{4}, 0.2$. Before autoclave, $\mathrm{pH}$ was adjusted to 6.0 with $1 \mathrm{~N} \mathrm{HCl}$ or $\mathrm{NaOH}$ solutions [4]. The cultivation condition was as the $\mathrm{Cz}$ medium.
HPLC Analysis for MPA Determination

MPA concentration was evaluated by a KNAUER HPLC (Germany) consisting of pump: LC-20 AD, auto sampler: SIL-20A, detector: SPD-20 A, degasser: DGU-20 A. The analysis was carried out with a $\mathrm{C}_{18}$ high persil column, at $40{ }^{\circ} \mathrm{C}$ and $250 \mathrm{~nm}$. The injection volume of $20 \mu \mathrm{L}$ with mobile phase consisted of $0.1 \mathrm{M} \mathrm{KH}_{2} \mathrm{PO}_{4}$ and acetonitrile at a ratio of 50:50, $\mathrm{pH} 3.0$ at a flow rate of $0.5 \mathrm{~mL} / \mathrm{min}$ was used [21, 22]. HPLC grade MPA (AppliChem) was used to prepare the calibration standard curve. Working standard solutions $(10-400 \mu \mathrm{g} / \mathrm{mL}$ ) were prepared from $1 \mathrm{mg} / \mathrm{mL}$ stock solution in HPLC grade methanol.

\section{Characterization of MPA Producing Strain}

Characterization of the selected MPA producer was performed based on morphological and microscopic properties as well as molecular analysis. After 7 days, some principles of the colony features including diameter, texture and color of conidia describing the morphology of Penicillium species, and degree of sporulation, the abundance of color and texture of mycelia, the presence and colors of soluble pigments and exudates were considered [23].

Colony characteristics on specific media are prominent features broadly used for species identification. MEA (Malt Extract Autolysate agar) [20] and CYA (Czapek Yeast Autolysate agar) [24] are recommended as standard media for Penicillium species isolation [23].

Penicillium strains with the highest MPA production were inoculated on the mentioned media in a three-point position and incubated at $25^{\circ} \mathrm{C}$ for 7 days. Colonies characteristics were recorded and compared with available identification keys [24].

A piece of agar $\left(1 \mathrm{~cm}^{2}\right)$ was placed on a sterile glass microscope slide. Then the slide was placed in a sterile Petrie dish to prevent contamination and drying during incubation. Some conidia were transferred to every four sides of the agar block and incubated at $25{ }^{\circ} \mathrm{C}$ for 5 days. Intact fruiting body structure, including phialides, hyphae and arrangement of conidia were observed after staining with lactophenol cotton blue [25].

\section{Molecular Analysis}

Genomic DNA was extracted using CTAB buffer containing: Tris, $10 \mathrm{mM}$; EDTA, $20 \mathrm{mM}$; CTAB, $0.02 \mathrm{M}$; NaCl, $0.8 \mathrm{M}$; Sorbitol, $0.13 \mathrm{M}$; PVP (Polyvinylpyrrolidone), $1 \%$.

For molecular characterization, both $18 \mathrm{~s}$ and ITS (internal transcribed spacer) regions of rRNA genes, as well as beta-tubulin gene were amplified using universal related primers, ITS1 (5'-TCCGTAGGTGAACCTGCGG-3'), ITS4 
(5'-TCCTCCGCTTATTGATATGC-3'), 18 s F (5'-CCTGGT TGATCCTGCCAGTA-3'), 18 s R (5'-GCTTGATCCTTC TGCAGGTT-3'), Bt2a (5'-GGTAACCAAATCGGTGCT GCTTTC-3') and Bt2b (5'-ACCCTCAGTGTAGTGACC CTTGGC- $3^{\prime}$ ), respectively.

PCR products were cloned in pTZ57R/T (Thermo scientific), sequenced and subjected to nBLAST against their fungal homologs.

The ITS sequence was subjected to phylogenetic analysis which was performed by molecular evolutionary genetics analysis (MEGA) software, version 7.0 using UPGMA method, with a bootstrap of 500 replicates.

\section{Results}

\section{Isolation of MPA Producing Penicillium Species}

To isolate a native MPA producing fungus, 140 Penicillium isolates were obtained from 50 samples of soil from forest, greenhouse, and agricultural lands of the various provinces of Iran, as well as 24 samples of moldy food, fruit and dairy products, as shown in Table 1.

\section{Evaluation of MPA Production}

HPLC method was used for the evaluation of MPA production by Penicillium isolates. Three MPA producing isolates were obtained as shown in Table 2. Twenty microliters of samples prepared from culture supernatants were injected into the HPLC column. Chromatograms of standard solution and GGST1 isolate with a retention time of $12 \mathrm{~min}$ is shown in Fig. 1. A comparison between two chromatograms confirmed that the GGST1 isolate has the ability of MPA production. Strains cultivation and MPA determination were repeated three times.
Table 2 MPA producing strains

\begin{tabular}{llc}
\hline MPA producing isolates & \multicolumn{2}{l}{ Average MPA production $(\mu \mathrm{g} / \mathrm{mL})$} \\
\cline { 2 - 3 } & Cz medium & Xu medium \\
\hline GGST1: P. glabrum IBRC- & 1079 & 371 \\
M 30518 & 522 & 53 \\
MP4 & 268 & 88 \\
FSM2 & \\
\hline
\end{tabular}

MPA production by selected strains in Xu medium was also evaluated. The results showed that 371,53 and $88 \mu \mathrm{g} /$ mL MPA were produced by GGST1, MP4 and FSM2 strains, respectively. Unexpectedly, all three strains were produced less quantities of MPA in Xu medium compared to the $\mathrm{Cz}$ medium as shown in Table 2 and Fig. 2.

\section{Characterization of the Best MPA Producing Isolate}

The MPA producer, GGST1 isolate, was identified based on its morphological (macroscopic and microscopic) characteristics as well as ITS, $18 \mathrm{~s}$ rDNA and beta-tubulin gene sequences.

The GGST1 strain colonies on CYA medium display $35-45 \mathrm{~mm}$ diameter, velvet surface, and radial white mycelium and produce grey-green conidia. The reverse color was in shades of grey to brown. On the other hand, on MEA medium, colonies with $40-50 \mathrm{~mm}$ diameter, velvet surface, radial grooves, white mycelium only in the center of the colony, high production of dark green conidia and sometimes secrete yellow exudates droplets were observed. Reverse color was yellow to yellow-orange. Furthermore, the stipes with 50-100 $\mu \mathrm{m}$ length and smooth walls with slight roughness, 10-12 flask-shaped phialides in a row with $8-12 \mu \mathrm{m}$ length and the smooth to finely roughness conidia with $3-5 \mu \mathrm{m}$ diameter were produced in long columns. These
Table 1 Number of Penicillium species isolated from various sources

\begin{tabular}{llll}
\hline Samples & Sampling sources & $\begin{array}{l}\text { Number of Penicillium } \\
\text { isolates }\end{array}$ & $\begin{array}{l}\text { Number of } \\
\text { MPA producing } \\
\text { isolates }\end{array}$ \\
\hline Soil & Fruit garden & 27 & 1 \\
& Forest and agricultural land & 33 & 1 \\
& Alfalfa farm & 8 & - \\
& Greenhouse & 13 & - \\
& Areas around the pharmaceutical & 17 & - \\
Moldy materials & company & 22 & - \\
& Fruits & 4 & - \\
& Grain & 16 & - \\
& Decayed cooked food & - & 3 \\
\hline \multirow{2}{*}{ Total } & Dairy product & 140 & \\
\hline
\end{tabular}


Fig. 1 HPLC chromatograms of a standard solution of HPLC grade MPA; b MPA produced by strain GGST1
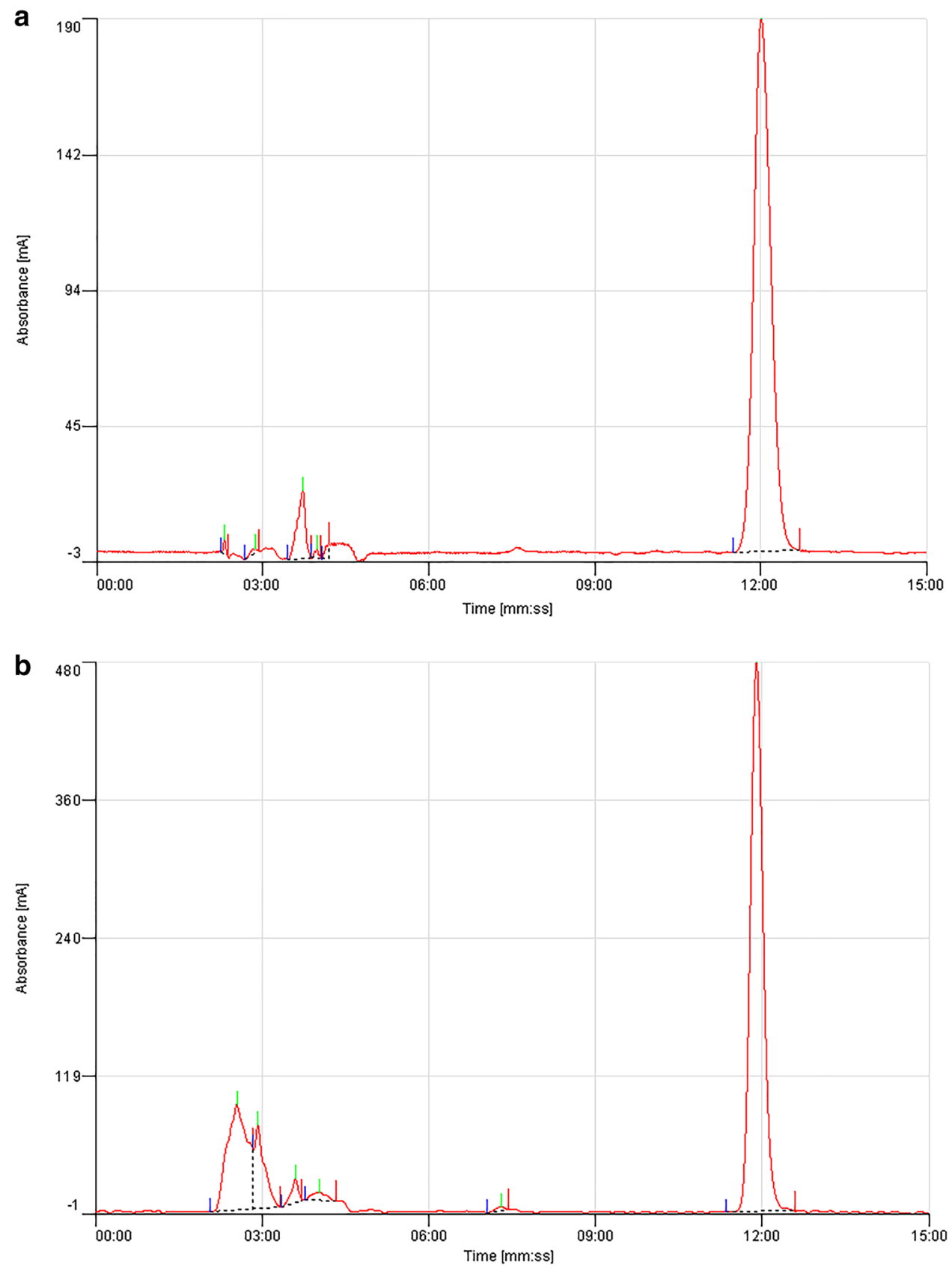

characteristics confirmed that the isolate belongs to $P$. glabrum species [26] (Fig. 3).

The sequences of amplicons from GGST1 isolate with sizes of 519, 1798 and 466 nucleotides were deposited in NCBI Genbank nucleotide sequence under accession numbers of MK611771 MN044770 and MW002460 for ITS, $18 \mathrm{~S}$ rDNA and beta-tubulin gene, respectively. The GGST1 isolate ITS sequence has $100 \%$ identity with many $P$. glabrum isolates ITS sequences, such as HLJ_16, Y56, ND70 and MS31-1. The 18S rDNA sequence has 99\% identity with $P$. glabrum strain KCTC16099 18S rDNA sequence. Furthermore, housekeeping beta-tubulin gene sequence of this isolate has $>99 \%$ identity with a number of $P$. glabrum strains such as 207P, KAS7776, KAS 7774 and many others. Therefore, the isolate was recognized as $P$. glabrum IBRC-M 30518 and kept for further studies and probable applications. The sequence was subsequently deposited in the GenBank (Accession Number MW002460).

\section{Phylogeny}

The phylogenetic position of the $P$. glabrum IBRC-M30518 was inferred from a comparison of its ITS sequence with the strains of $P$. verhagenii, $P$. saturniforme, $P$. bussumense, $P$. 


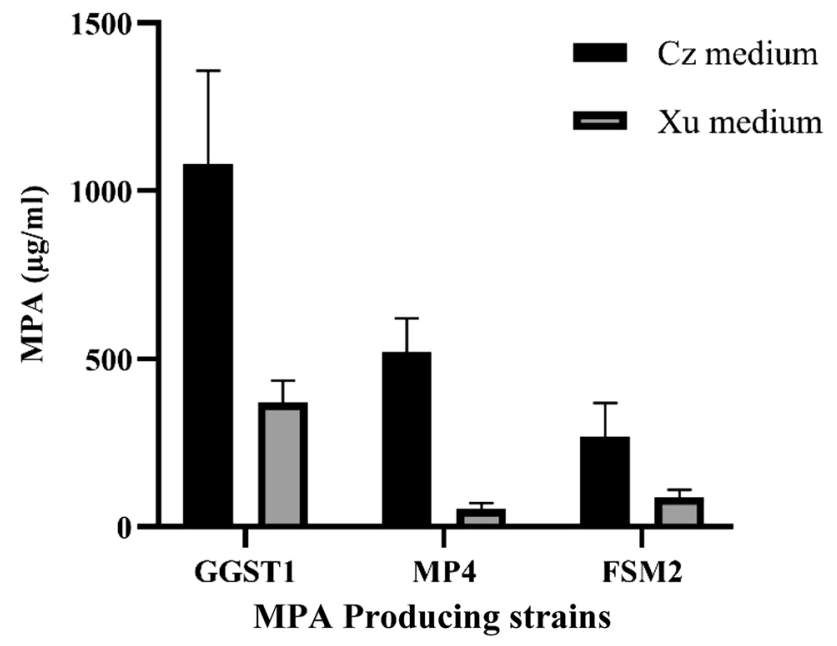

Fig. 2 Comparison of MPA production in two different media. $\mathrm{Cz}$ and $\mathrm{Xu}$ media are displayed in black and gray, respectively

pulvis, $P$. rudallense, $P$. armarii, $P$. purpurascense, $P$. spinulosum, $P$. vagum, $P$. tsitsikamaense, $P$. fuscum, $P$. sublectaticum, P. adametzii, P. camemberti, P. glabrum, P. thomii, $P$. commune, $P$. solitum, $P$. chrysogenum, $P$. kewense, $P$. freii, $P$. expansum, $P$. roqueforti, and $P$. brevicompactum (Fig. 4 ). Like the type strain of $P$. glabrum, the newly isolated strain belonged to the Aspergilloides clade, which is defined by characteristics such as possessing monoverticillate conidiophores and growing moderately or quickly on agar media. According to Houbraken et al. the most important feature distinguishing members of this section are colony size on agar media, growth at $30^{\circ} \mathrm{C}$, ornamentation and shape of conidia, sclerotium production and stipe roughness [26].

\section{Discussion}

Filamentous fungi are widely associated with the ability to produce bioactive secondary metabolites that have important pharmaceutical applications [27]. One of the most extensive genera of filamentous fungi is Penicillium, with more than 354 accepted species [23], many of which are in high importance due to their ability to the production of pharmaceuticals and industrial agents as secondary metabolites. One of such prominent secondary metabolites is MPA, produced by several Penicillium species such as P. brevicompactum, $P$. roqueforti, $P$. puberulum, and $P$. stoloniferum as well as other fungi Byssochlamys nivea and Aspergillus strains [28-31].

There are plenty of reports implying the isolation of various strains of Penicillia from soil and moldy foods and fruits, with the aim of MPA production (Table 3). Despite the large implication of the P. glabrum in food contamination, some studies have been conducted to investigate its ability to enzyme production [32, 33]. Meanwhile, there is no report on MPA production by $P$. glabrum.

According to Landeweert et al. $\geq 99 \%$ of sequence identity was identified to species level, 95-99\% to genus level, and $\leq 95 \%$ to family level [34]. The ITS sequence (partial sequence of ITS 1, complete sequence of $18 \mathrm{~S}$ ribosomal RNA gene and ITS 2, and partial sequence of large subunit ribosomal RNA gene), were analyzed using nBLAST in NCBI search tool and demonstrated that this isolate could be assigned to series of species including P. glabrum, P. spinulosum, $P$. aragonense, $P$. expansum, $P$. spinuloramigenum and many others. Regarding some studies, ITS sequence is not sufficient for identification at the species level, therefore houskeeping beta-tubulin gene was sequenced and compared with their fungal homologs. The result demonstrates that this isolate could be assigned to P. glabrum (GenBank Accession Number EU128574.1) with an identity of 99.57\%. A phylogenetic analysis using the ITS region revealed that the newly isolated stain is belonged to the species P. glabrum, Which is considered as one of the top three well characterized members of the section Aspergilloides, along with P. spinulosum and $P$. thomii. These worldwide distributed species, constituting 3 out of 12 clades of the section, could be isolated from many substrates including soil, food, bark and indoor environments [26]. The majority of members of the section Aspergilloides are predominantly monoverticillate and most grow quickly on agar media [35]. According to phenotypical features, the species from $P$. glabrum-clade represent a remarkable relation to those of the $P$. spinulosum-clade. Yet, they could be distinct based on colony texture, as the colony surface is defined "strictly velvety" for P. glabrum, and be "loose textured" for P. spinulosum [26].

According to some studies, the highest reported MPA production is related to $P$. brevicompactum ATCC 16024 strain [21], producing $5900 \mathrm{mg} / \mathrm{L} \mathrm{MPA}$ in an Xu medium in $250 \mathrm{~mL}$ shake flask [4].

The local $P$. glabrum IBRC-M 30518 strain isolated in this study is the first report of MPA production by this species which can produce $1079 \mathrm{mg} / \mathrm{L} \mathrm{MPA}$ in $\mathrm{Cz}$ medium. Although its production yield is less than P. brevicompactum ATCC 16024 strain, but it is more than most of the MPA producing species previously reported [21]. Two other Penicillium strains, MP4 and FSM2 produced 522 and $268 \mathrm{mg} / \mathrm{L}$ MPA in $\mathrm{Cz}$ medium, respectively. Meanwhile, MPA production of these three Penicillium isolates in $\mathrm{Xu}$ medium (the optimum medium for $P$. brevicompactum ATCC 16024) was much lower than in $\mathrm{Cz}$ medium as shown in Table 2 [4].

Therefore, it seems necessary to develop a process for the improvement of MPA production by the local P. glabrum IBRC-M 30518. To enhance MPA production with $P$. glabrum IBRC-M 30518, medium and process optimization are the next steps in our research which is in the way. Genetic manipulation and mutation-selection approaches can also be 

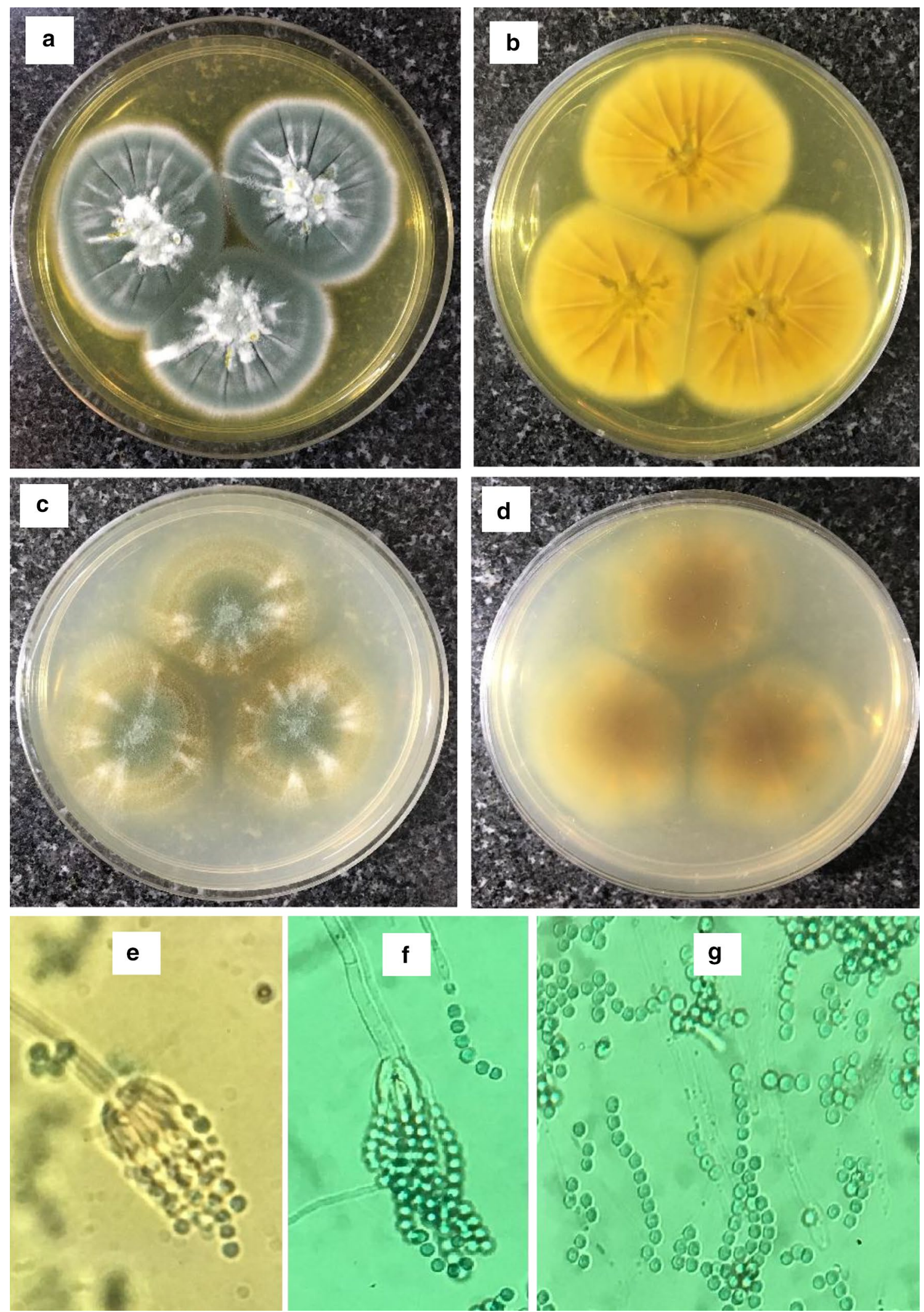

Fig. 3 Penicillium GGST1, cultures incubated for 7 days at $25^{\circ} \mathrm{C}$. a Obverse MEA, b reverse MEA, c obverse CYA, d reverse CYA. e-g Conidiophores, phialides and conidia. Scale bar $=10 \mu \mathrm{m}$ 
Fig. 4 Cladogram based on the ITS sequences which is obtained using MEGA. Pg-ITS refers to the sequence from newly isolated strain. The other sequences are belonged to the TYPE strains of related species, classified in distinct sections

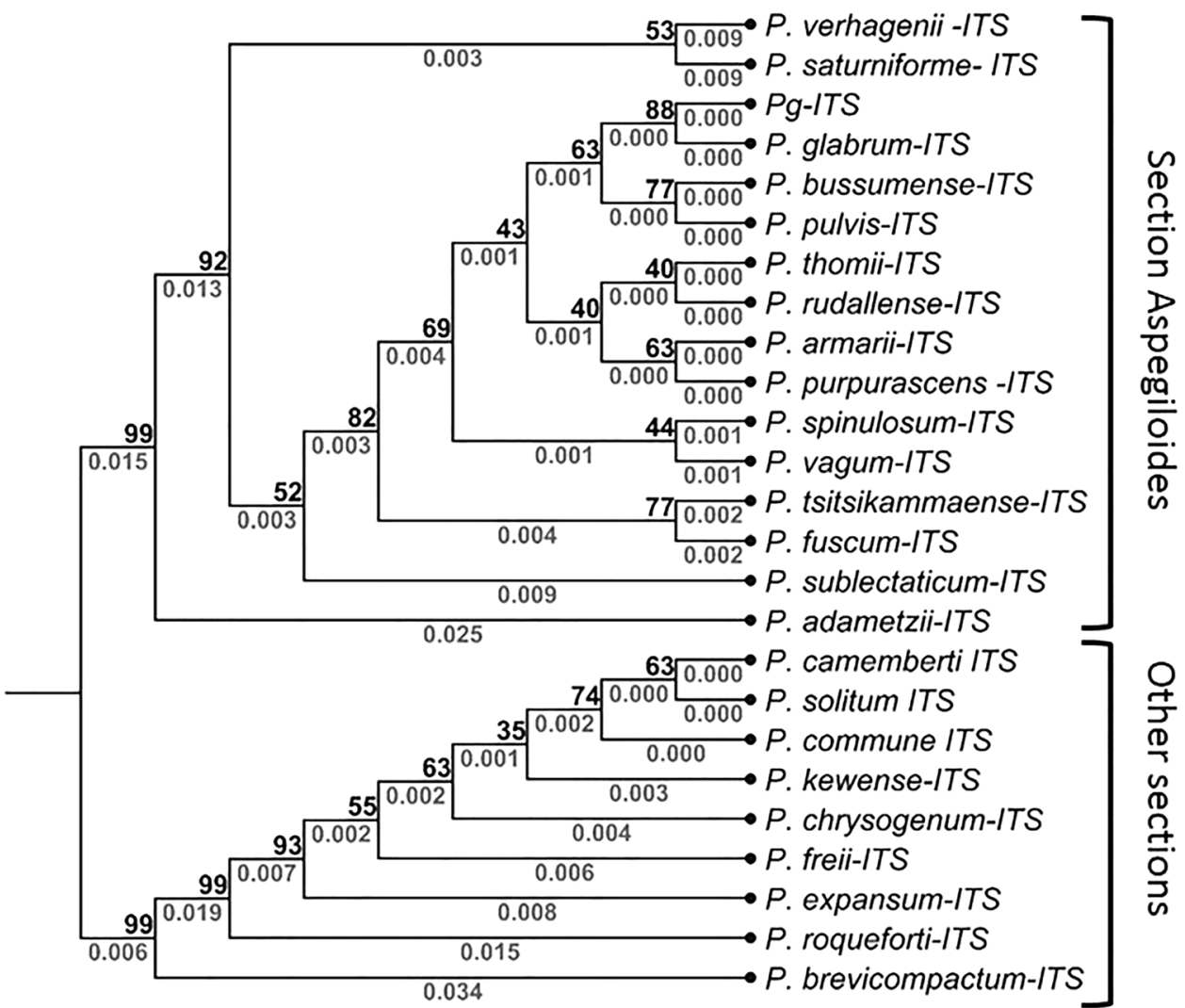

\begin{tabular}{|c|c|c|c|}
\hline Source & Isolated strain(s) & MPA titer & References \\
\hline Mouldy maize & P. brevicompactum & - & [37] \\
\hline Blue-molded cheeses ${ }^{\mathrm{a}}$ & P. roqueforti & $800-4000 \mathrm{mg} / \mathrm{kg}$ & [10] \\
\hline Silage $^{a}$ & P. roqueforti & $0.02-35 \mathrm{mg} / \mathrm{kg}$ & [38] \\
\hline $\begin{array}{l}\text { Food wastes: } \\
\text { Cereals, fruits, meat, vegetables } \\
\text { Fruits, cheese, bread } \\
\text { Cereals, bread, meat }^{\mathrm{a}}\end{array}$ & $\begin{array}{l}\text { P. brevicompactum } \\
\text { P. roqueforti } \\
\text { p. carneum }\end{array}$ & $0.075-19 \mathrm{mg} / \mathrm{kg}$ & [39] \\
\hline Infected ginger & P. brevicompactum & - & [9] \\
\hline Tap water & P. brevicompactum & - & [40] \\
\hline Air intake, Insect ${ }^{\mathrm{a}}$ & Aspergillus strains & $1-3 \mathrm{mg} / \mathrm{kg}$ & [31] \\
\hline Oilseed cakes and indoor air ${ }^{\mathrm{a}}$ & Aspergillus pseudoglaucus & $1-17 \mathrm{mg} / \mathrm{kg}$ & [30] \\
\hline Mould-ripened cheese $^{a}$ & Penicillium roqueforti & $0.1-23.1 \mathrm{mg} / \mathrm{kg}$ & [41] \\
\hline Grapevine garden soil & P. glabrum & $1079 \mathrm{mg} / \mathrm{L}$ & This study \\
\hline
\end{tabular}

${ }^{\text {a }}$ Production of MPA on solid media
Table 3 The strains that produce MPA used for future improvement of the local $P$. glabrum IBRCM 30518 and possibly low-cost production of MPA [36].

The growth rate of isolated strains was higher and produced more biomass on MEA compared to CYA, in the same time and conditions. This result suggested that, the MEA medium could be a base for medium optimization.

In conclusion, this research was conducted to isolate native MPA producer strains and then identification of the highest producer by colony morphology combined with molecular analysis. This is the first report showing that $P$. glabrum IBRC-M 30518 can produce this antibiotic which is worthy of further study. However, this assay needs further investigation for large scale production of MPA.

Acknowledgements The authors are grateful to Dr. Mehrdad Abbasi, faculty member of the Iranian Research Institute of Plant Protection for his great help and useful comments. 
Author Contributions FM: Doing laboratory works and preparing the initial draft of the article. AS: Collaborating in doing laboratory works and preparing the initial draft of the article. BY: Co-research design and supervision and also article editor. SA: Collaboration in laboratory work and preparation of article draft. SSF: Research design and supervision and also article final editor.

Funding This study was funded by the National Institute of Genetic Engineering and Biotechnology (NIGEB) (Grant Nos. 572 and 627).

\section{Declarations}

Conflict of interest The authors declare that they have no conflict of interest.

\section{References}

1. Holt CD (2017) Overview of immunosuppressive therapy in solid organ transplantation. Anesthesiol Clin 35(3):365-380. https:// doi.org/10.1016/j.anclin.2017.04.001

2. Takahashi K, Go P, Stone CH, Safwan M, Putchakayala KG, Kane WJ, Malinzak LE, Kim DY, Denny JE (2017) Mycophenolate mofetil and pulmonary fibrosis after kidney transplantation: a case report. Am J Case Rep 18:399-404. https://doi.org/10.12659/ AJCR.902380

3. Wang Y, Zhou X, Debing Y, Chen K, Van Der Laan LJ, Neyts J, Janssen HL, Metselaar HJ, Peppelenbosch MP, Pan Q (2014) Calcineurin inhibitors stimulate and mycophenolic acid inhibits replication of hepatitis E virus. Gastroenterology 146(7):1775-1783. https://doi.org/10.1053/j.gastro.2014.02.036

4. Xu Z-N, Yang S-T (2007) Production of mycophenolic acid by Penicillium brevicompactum immobilized in a rotating fibrous-bed bioreactor. Enzyme Microb Technol 40(4):623-628. https://doi. org/10.1016/j.enzmictec.2006.05.025

5. Kato F, Matsuyama S, Kawase M, Hishiki T, Katoh H, Takeda M (2020) Antiviral activities of mycophenolic acid and IMD-0354 against SARS-CoV-2. Microbiol Immunol 64:635-639. https:// doi.org/10.1111/1348-0421.12828

6. Jonsson CA, Carlsten H (2003) Mycophenolic acid inhibits inosine 5'-monophosphate dehydrogenase and suppresses immunoglobulin and cytokine production of B cells. Int Immunopharmacol 3(1):31-37. https://doi.org/10.1016/S1567-5769(02)00210-2

7. García-Estrada C, Martín J-F (2016) Biosynthetic gene clusters for relevant secondary metabolites produced by Penicillium roqueforti in blue cheeses. Appl Microbiol Biotechnol 100(19):8303-8313. https://doi.org/10.1007/s00253-016-7788-x

8. Vinokurova N, Ivanushkina N, Kochkina G, Arinbasarov M, Ozerskaya S (2005) Production of mycophenolic acid by fungi of the genus Penicillium link. Appl Biochem Microbiol 41(1):83-86. https://doi.org/10.1007/s10438-005-0015-7

9. Overy DP, Frisvad JC (2005) Mycotoxin production and postharvest storage rot of ginger (Zingiber officinale) by Penicillium brevicompactum. J Food Prot 68(3):607-609. https://doi.org/10. 4315/0362-028X-68.3.607

10. Lafont P, Debeaupuis J-P, Gaillardin M, Payen J (1979) Production of mycophenolic acid by Penicillium roqueforti strains. Appl Environ Microbiol 37(3):365-368. https://doi.org/10.1128/AEM. 37.3.365-368.1979

11. Kure CF, Skaar I, Brendehaug J (2004) Mould contamination in production of semi-hard cheese. Int J Food Microbiol 93(1):4149. https://doi.org/10.1016/j.ijfoodmicro.2003.10.005

12. Ndagijimana M, Chaves-López C, Corsetti A, Tofalo R, Sergi M, Paparella A, Guerzoni M, Suzzi G (2008) Growth and metabolites production by Penicillium brevicompactum in yoghurt. Int J Food Microbiol 127(3):276-283. https://doi.org/ 10.1016/j.ijfoodmicro.2008.07.019

13. Knob A, Beitel SM, Fortkamp D, Terrasan CRF, Almeida AFd (2013) Production, purification, and characterization of a major Penicillium glabrum xylanase using brewer's spent grain as substrate. Biomed Res Int. https://doi.org/10.1155/2013/728735

14. Nevarez L, Vasseur V, Le Madec A, Le Bras M, Coroller L, Leguérinel I, Barbier G (2009) Physiological traits of Penicillium glabrum strain LCP 085568 a filamentous fungus isolated from bottled aromatised mineral water. Int J Food Microbiol 130(3):166-171. https://doi.org/10.1016/j.ijfoodmicro.2009.01. 013

15. Azaz AD (2003) Isolation and identification of soilborne fungi in fields irrigated by GAP in Harran plain using two isolation methods. Turk J Bot 27(2):83-92

16. Fraga M, Zonta E, Balieiro F (2011) Isolation and selection of filamentous fungi from petroleum contaminated soil. Biores Bull 4:227-235

17. Scudamore K, Clarke J, Hetmanski M (1993) Isolation of Penicillium strains producing ochratoxin $\mathrm{A}$, citrinin, xanthomegnin, viomellein and vioxanthin from stored cereal grains. Lett Appl Microbiol 17(2):82-87. https://doi.org/10.1111/j.1472-765X. 1993.tb00377.x

18. Ghiasian SA, Rezayat SM, Kord-Bacheh P, Maghsood AH, Yazdanpanah H, Shephard GS, Van Der Westhuizen L, Vismer HF, Marasas WF (2005) Fumonisin production by Fusarium species isolated from freshly harvested corn in Iran. Mycopathologia 159(1):31-40. https://doi.org/10.1007/s11046-004-3899-5

19. Bartman C, Doerfler D, Bird B, Remaley A, Peace J, Campbell I (1981) Mycophenolic acid production by Penicillium brevicompactum on solid media. Appl Environ Microbiol 41(3):729-736. https://doi.org/10.1128/AEM.41.3.729-736.1981

20. Raper KB, Thom C (1949) A manual of the Penicillia. Baillière, Tindall \& Cox, London

21. Ardestani F, Fatemi SS, Yakhchali B, Hosseyni SM, Najafpour G (2010) Evaluation of mycophenolic acid production by Penicillium brevicompactum MUCL 19011 in batch and continuous submerged cultures. Biochem Eng J 50(3):99-103. https://doi.org/ 10.1016/j.bej.2010.03.008

22. Elbarbry FA, Shoker AS (2007) Therapeutic drug measurement of mycophenolic acid derivatives in transplant patients. Clin Biochem 40(11):752-764. https://doi.org/10.1016/j.clinbiochem. 2007.03.006

23. Visagie C, Houbraken J, Frisvad JC, Hong S-B, Klaassen C, Perrone G, Seifert K, Varga J, Yaguchi T, Samson R (2014) Identification and nomenclature of the genus Penicillium. Stud Mycol 78:343-371. https://doi.org/10.1016/j.simyco.2014.09.001

24. Pitt JI (1988) A laboratory guide to common Penicillium species. CSI Res Org Div Food Processing, North Ryde

25. Johnston PR, Jones D (1997) Relationships among Colletotrichum isolates from fruit-rots assessed using rDNA sequences. Mycologia 89(3):420-430. https://doi.org/10.1080/00275514.1997.12026 801

26. Houbraken J, Visagie C, Meijer M, Frisvad JC, Busby P, Pitt J, Seifert K, Louis-Seize G, Demirel R, Yilmaz N (2014) A taxonomic and phylogenetic revision of Penicillium section aspergilloides. Stud Mycol 78:373-451. https://doi.org/10.1016/j.simyco. 2014.09.002

27. Nielsen JC, Grijseels S, Prigent S, Ji B, Dainat J, Nielsen KF, Frisvad JC, Workman M, Nielsen J (2017) Global analysis of biosynthetic gene clusters reveals vast potential of secondary metabolite production in Penicillium species. Nat Microbiol 2(6):17044. https://doi.org/10.1038/nmicrobiol.2017.44

28. Patel G, Biswas K, Patil MD, Chisti Y, Banerjee UC (2018) Bioreactor studies of production of mycophenolic acid by Penicillium 
brevicompactum. Biochem Eng J 140:77-84. https://doi.org/10. 1016/j.bej.2018.09.007

29. Burkin A, Kononenko G (2010) Producers of mycophenolic acid in ensiled and grain feeds. Appl Biochem Microbiol 46(5):545550. https://doi.org/10.1134/S0003683810050145

30. Séguin V, Gente S, Heutte N, Vérité P, Kientz-Bouchart V, Sage L, Goux D, Garon D (2014) First report of mycophenolic acid production by Eurotium repens isolated from agricultural and indoor environments. World Mycotoxin J 7(3):321-328. https://doi.org/ 10.3920/WMJ2013.1619

31. Mouhamadou B, Sage L, Périgon S, Séguin V, Bouchart V, Legendre P, Caillat M, Yamouni H, Garon D (2017) Molecular screening of xerophilic Aspergillus strains producing mycophenolic acid. Fungal Biol 121(2):103-111. https://doi.org/10.1016/j. funbio.2016.10.001

32. Van de Lagemaat J, Pyle D (2005) Modelling the uptake and growth kinetics of Penicillium glabrum in a tannic acid-containing solid-state fermentation for tannase production. Process Biochem 40(5):1773-1782. https://doi.org/10.1016/j.procbio.2004.06.044

33. Barreto M, Houbraken J, Samson R, Frisvad JC, San-Romão M (2011) Taxonomic studies of the Penicillium glabrum complex and the description of a new species $P$. subericola. Fungal Divers 49(1):23-33. https://doi.org/10.1007/s13225-011-0090-4

34. Landeweert R, Leeflang P, Kuyper TW, Hoffland E, Rosling A, Wernars K, Smit E (2003) Molecular identification of ectomycorrhizal mycelium in soil horizons. Appl Environ Microbiol 69(1):327-333. https://doi.org/10.1128/AEM.69.1.327-333.2003

35. Houbraken J, Samson R (2011) Phylogeny of Penicillium and the segregation of trichocomaceae into three families. Stud Mycol 70:1-51. https://doi.org/10.3114/sim.2011.70.01

36. Dong Y, Zhang J, Xu R, Lv X, Wang L, Sun A, Wei D (2016) Insertion mutation in HMG-CoA lyase increases the production yield of MPA through agrobacterium tumefaciens-mediated transformation. J Microbiol Biotechnol 26(11):1924-1932. https://doi. org/10.4014/jmb.1603.03038

37. Clutterbuck PW, Oxford AE, Raistrick H, Smith G (1932) Studies in the biochemistry of micro-organisms: the metabolic products of the Penicillium brevicompactum series. Biochem J 26(5):1441. https://doi.org/10.1042/bj0261441

38. Schneweis I, Meyer K, Hörmansdorfer S, Bauer J (2000) Mycophenolic acid in silage. Appl Environ Microbiol 66(8):36393641. https://doi.org/10.1128/AEM.66.8.3639-3641.2000

39. Rundberget T, Skaar I, Flåøyen A (2004) The presence of Penicillium and Penicillium mycotoxins in food wastes. Int J Food Microbiol 90(2):181-188. https://doi.org/10.1016/S0168-1605(03) 00291-5

40. Gonçalves AB, Paterson RRM, Lima N (2006) Survey and significance of filamentous fungi from tap water. Int J Hyg Environ Health 209(3):257-264. https://doi.org/10.1016/j.ijheh.2005.12. 001

41. Cakmakci S, Gurses M, Hayaloglu AA, Cetin B, Sekerci P, Dagdemir E (2015) Mycotoxin production capability of Penicillium roqueforti in strains isolated from mould-ripened traditional Turkish civil cheese. Food Addit Contam 32(2):245-249. https:// doi.org/10.1080/19440049.2014.997808

Publisher's Note Springer Nature remains neutral with regard to jurisdictional claims in published maps and institutional affiliations. 